\title{
Las máximas conversacionales desde un enfoque cognitivo: algunos casos del discurso indirecto en castellano
}

Palabras clave: discurso indirecto encubierto, intercambio conversacional, máximas conversacionales, denegación plausible, implicaturas conversacionales

El panorama de los últimos cincuenta años de lingüística aplicada presenta una constante preocupación por el fenómeno del discurso indirecto sea en su vertiente discursiva orientada hacia el análisis de series sintagmáticas de constituyentes dentro de un discurso referido ${ }^{1}$ sea en su dimensión pragmática ${ }^{2}$ centrada en la estructuración implícita del mensaje comunicativo como el paradigma de una enunciación indirecta. Desde el enfoque pragmático, la teoría de las máximas de cooperación y la teoría de la cortesía han investigado el discurso indirecto desde el enfoque conversacional visto como un fenómeno social donde los interlocutores se empeñan en construir un significado mútuo en un intercambio interpersonal respetando en alguna medida, las máximas conversacionales. Estas teorías se han visto complementadas por nuevos enfoques que en los últimos años han supuesto los modelos cognitivistas que se han centrado sobre todo en los modos de procesamiento mental de una enunciación indirecta y el coste emocional implicado (Pinker, 1994; Pinker, Nowak y Lee, 2008; Pinker y Lee, 2010).

$1 \quad$ Entre las teorías que se han ocupado del análisis de la dinámica entre funciones disursivas cabe nombrar, en orden de importancia para la presente investigación: la teoría de la deixis (Benvéniste, 1974; Bühler, 1934), la teoría de polifonía (Bajtín, 1981) y los modelos interaccionistas (Goffman, 1975).

2 Entre las teorías pragmáticas, cabe destacar las que han analizado el intercambio comunicativo como un fenómeno social-interactivo: la teoría de los principios (las máximas) de cooperación de Grice (1975), recogida y revisada más tarde por Sperber y Willson (1994), la teoría de los actos de habla (Austin, 1962; Searle, 1969) y la teoría de la cortesía (Brown y Levinson, 1987). 
El objetivo de este trabajo es, en primer lugar señalar, a través de un panorama de enfoques aplicados al análisis de casos concretos del discurso indirecto en castellano, el avance que ha supuesto el tránsito de la teoría griceana al enfoque cognitivista recogido en la teoría de denegación plausible (Pinker, Nowak y Lee, 2008; Pinker y Lee, 2010) para obtener una descripción más precisa del fenómeno y, en segundo lugar, intentar diseñar un modelo más exhaustivo de la clasificación del discurso indirecto encubierto dentro del panorama de estrategias psicolingüísticas que usa el hablante para mitigar sus intenciones y preferencias afectivas, cognitivas y socioéticas.

\section{El discurso indirecto: división pragmática y discursiva del fenómeno}

Parece necesario, de entrada, precisar algunas cuestiones terminológicas que se refieren al concepto del discurso indirecto (también: el discurso referido o el estilo indirecto) en la extensa bibliografía sobre este fenómeno sintáctico, discursivo y pragmático. Sin tener que centrar el interés del presente artículo en una explicación detallada de la función sintáctica del estilo indirecto dentro del sistema de la oración compuesta en castellano, cabe proponer algunas precisiones terminológicas. A lo largo de este trabajo nos referimos al discurso indirecto como un fenómeno pragmático-discursivo, a cambio de su dimensión sintáctica en el sentido estrecho de la palabra (Real Academia Española: 2010). Ésta supone el tipo del discurso donde las palabras se dirigen o se refieren al interlocutor indirectamente a través de un enunciador que reproduce el texto con sus propias palabras. El discurso indirecto desde un concepto pragmático, en cambio, se refiere indirectamente al propio sentido (directo, denotativo) de la enunciación que en un contexto comunicativo, modificado, por cada uno de los interlocutores agrega sentidos connotativos adicionales, eso es las implicaturas (Grice, 1975: 306). La decisión de mantener una visión pragmática del fenómeno estriba en el hecho de que parece abarcar dos dimensiones del discurso indirecto: la pragmática en el sentido estrecho y la discursiva. Cada cambio del interlocutor significa inevitablemente también un cambio de las circunstancias de la enunciación y consecuentemente, la modificación de la intención discursiva. El discurso indirecto, analizado desde el punto de vista pragmático, sirve además para explicar los significados implícitos que se generan en un contexto extralingüístico en el que el interlocutor debe buscar patrones de interpretación cada vez que cambia la intención o el contexto de la enunciación en dirección opuesta, eso es, cuando los interlocutores dejan de cooperar según los principios de cooperación. 


\section{El discurso indirecto desde una dimensión sociopragmática}

La dimensión social del discurso indirecto se deriva de la concepción sociopragmática del lenguaje humano como código de relaciones humanas que se articula en unos intercambios comunicativos y cuyo éxito depende del esfuerzo de los interlocutores invertido para descifrar exhaustivamente el mensaje emitido ${ }^{3}$.

En la teoría de Grice (1989: 43), el discurso indirecto viene relacionado estrechamente con el concepto de la implicatura, el significado connotativo e intencionado del emisor que discrepa del significado denotativo verbalizado y cuyo valor semántico secundario se puede obtener de éste solo indirectamente mediante el proceso de la inducción desenmarcándolo del contexto situacional y los códigos convencionales o culturales que determinan su semántica: «In some cases the conventional meaning of the words used will determine what is implicated besides helping to determine what is said» (Grice, 1989: 44).

El criterio de la convencionalidad determina el primer gran grupo de las implicaturas que reciben el nombre de las implicaturas convencionales precisamente por su característica inherente de disponer de un significado convencional que puede ser interpretado de manera unívoca si el receptor maneja las mismas claves culturales que el emisor del mensaje (eso es, conoce la convención que une el significado del mensaje a la expresión). En este grupo se enmarcan las fórmulas de la cortesía (con el valor semántico-pragmático de la solicitud, la propuesta o mandato) en forma de preguntas indirectas:

(1) «jOye, no te importaría de verdad ya que estás aquí bueno pues me tocas el mamotreto este me lo tocas y me arreglas unos días?» (solicitud indirecta, Esta Noche Pedro, 1986, CREA)

(2) «¿Como tú estás siempre con tu familia, ¿jpor qué no te vienes este año conmigo??» (propuesta indirecta, Universidad Alcalá de Henares, 2003, CREA)

(3) « ¿Cogí el permiso y me dice Jabardo dice: ¿por qué no te vas a la...a la pastelería lo el mes este del permiso? [...] Bueno, pues vete sobre las ocho y media de la tarde.» (mandato indirecto, Universidad Alcalá de Henares, 2003, CREA)

3 El concepto sociopragmático del lenguaje humano se inspira en parte en las teorías interaccionistas antropológicas de Goffmann (1975) que atribuye el principio fundamental de mantener las relaciones interpersonales humanas, entre otras, la conversación, al esfuerzo constante de proteger la imagen pública (face) ante el otro en transiciones interpersonales. 
Según Grice, las implicaturas convencionales difieren sustancialmente del segundo gran grupo de las implicaturas conversacionales (no convencionales) cuyo significado es arbitrario y depende de los factores discursivos mismos que intervienen en la creación del mensaje (los factores psicolingüísticos, como son, por ejemplo, la percepción y la recepción afectivas en el emisor y el receptor) por lo que su semántica viene marcada por la ausencia de un código cultural común que facilitara un conocimiento compartido suficiente para poder interpretar el significado común por convención. Se rigen, por otro lado, por una serie de principios discursivos que la teoría griceana pudo catalogar bajo cinco "máximas conversacionales" y otros principios contextuales (psicolingüísticos y sociales):

There are, of course, all sorts of maxims (aesthetic, social or moral in character), such as 'Be polite', that are normally observed in a talk exchange between the participants, and these too can also generate non-conventional implicatures. The conversational maxims and the conversational implicatures are specially connected, I hope, with the particular changes that talk, (and so talk exchange), is adapted to serve and is primarily employed to serve. (Grice, 1975: 308)

En ausencia de un código convencional, los interlocutores deben respetar las cinco máximas que posibilitan que el mensaje sea efectivo y adecuadamente percibido por todos los participantes del intercambio comunicativo y no solo por los miembros de una comunidad cultural, a saber: la máxima de la cantidad (el mensaje debe ser cuanto más informativo y no redundante), la máxima de la calidad (los mensajes deben ser verosímiles), la máxima de la relevancia (se deben evitar los mensajes no pertinentes a la conversación) y la máxima del modo (que pretende garantizar la claridad, desambiguación y la precisión con la sencillez de la expresión del mensaje). (Grice, 1975: 308)

Se postula que el éxito de la cooperación entre los interlocutores en un intercambio depende de la medida en que las enunciaciones sean perfectamente relevantes, verosímiles, proporcionadas y claras. Ahora bien, solo las manifestaciones del discurso directo pueden mantenerse dentro de los límites de la cooperación, siguiendo estrictamente los principios, ya que cualquier desambiguación del contexto, sea él de la emisión sea el de la recepción, genera asimetría en esta relación infringiendo los principios y abandonando la posibilidad de cooperar. En la gran mayoría de las implicaturas, bien conversacionales bien convencionales los principios quedan transgredidos para, a coste de 
una menor efectividad discursiva ganar una mayor integridad y beneficio en el campo social, moral o afectivo. Los motivos sociales de tal procedimiento discursivo han sido extensamente analizados por Brown y Levinson (1987) y Leech $(1983)^{4}$ en sus trabajos sobre la cortesía verbal como una de las estrategias que se usa para mitigar la discrepancia entre la intención emitida por el emisor y su recepción en relación con el daño a la imagen social que le pueda ocasionar al receptor en situaciones éticamente delicadas. El éxito en la conservación de una imagen pública positiva es mayor en cuanto más encubierta sea la propuesta que amenaza la imagen del interlocutor $\mathrm{y}$, en cambio, menor en propuestas que amenazan directamente su integridad (imagen pública negativa). Esta correlación entre las situaciones moralmente comprometidas que rigen una expresión asimétrica, adversa o indirecta con el respecto a la intención comunicativa y la violación de las máximas conversacionales se pone patente en estilo indirecto encubierto, como demuestran los siguientes casos:

(4) En resumen, los temas en los que aparece la mujer como sujeto activo se han ampliado considerablemente. (discriminación encubierta; Pontificia Universidad Catolica de Perú, 1993, CREA)

(5) Nos gustaría haber estado con usted muchos más minutos, pero el tiempo es inexorable. (cordialidad falsa o fingida; Radio Madrid, /07/12/1991, CREA)

(6) El sastre, a pesar de ser tuerto y lleno de picaduras de viruela por toda la cara, ejercía con bastante éxito la confección de uniformes y todos los demás fracos y pantalones. (recomendación falsa y paródica para ejercer un oficio; Gogol, 1959: 365)

(7) Pero a lo mejor le haría ilusión que fuera usted, él que designara el partido, digo yo. (información redundante para solicitar un favor; TVE 1, /14/03/1989, CREA)

La dimensión social de los intercambios comunicativos se ha visto completada en las investigaciones dentro del campo de las teorías de la cortesía que han revisado y perfeccionado el sistema de las máximas de Grice en términos de garantizar no solo una emisión segura de la información, sino también en términos de proponer maneras para asegurar una información aceptable en condiciones donde el intercambio comunicativo puede poner a riesgo las relaciones interpersonales de los hablantes y que por lo tanto, rige estrategias dentro de la lengua para mitigar el daño o el riesgo público potencial.

4 En concepto de Leech, el éxito de la enunciación en términos de la cortesía corresponde a una negociación del beneficio del emisor y el coste respectivo del receptor; cuanto menor sea el coste y mayor el benificio, más cortés resulta la enunciación. 


\section{El discurso indirecto desde la dimensión cognitivista}

\subsection{La teoría de la denegación plausible}

En el panorama de las teorías de la cortesía y cooperación, las diferentes formas del discurso indirecto o implícito corresponden a una organización discursiva específica que no se refiere literalmente a la proposición, y entienden el uso de diferentes tipos de enunciación según el grado de explicitud, a saber; el estilo indirecto encubierto 5 (arbitrario y oblicuo) que se diferencian en cuanto al nivel de la convención semántica de las formas del estilo indirecto desvelado ${ }^{6}$ (canónico y prototípico) (Pinker, 2008: 785).

Cada una de las teorías se ha prestado a explicar, siempre desde la perspectiva de sus doctrinas de investigación respectivas, las relaciones entre la forma de la enunciación y el significado intencionado del hablante. En relación con el último, han centrado su interés en buscar motivos de posibles discrepancias en la manera de codificar el significado por parte del emisor y su recuperación durante el proceso de la decodificación por parte del receptor que generan distorsiones comunicativas, los significados implícitos o no expresos y el fenómeno del discurso indirecto. La teoría de la cortesía ha explorado los motivos sociales del uso de las formulas indirectas de cortesía para defender la imagen social del hablante como recompensa de haber expuesto una intención que posiblemente resulte comprometida para el receptor y atenuar un efecto de rebote negativo. La teoría de la cooperación ha estudiado el discurso indirecto desde la perspectiva del principio de cooperación, sobre todo en lo que se refiere a la puesta en marcha de las máximas conversacionales y su violación como uno de los rasgos inherentes del discurso indirecto (que por definición trasgrede las máximas de modo que abogan por una enunciación clara y no ofuscada). (Grice, 1975: 313)

Lo que le mueve al hablante para optar por el estilo indirecto en estos casos es el grado de carga emotiva y responsabilidad asumida por el hablante por la posibilidad de cometer un acto poco ético y como consecuencia arriesgar una posible estigmatización. Si el grado de rechazo a la proposición es alto, el hablante tiene que recurrir a otro nivel de cooperación - él de la ambigüedad, proposiciones indirectas y metáforas que por mucho que vayan en contra

5 De aquí en adelante: el discurso indirecto encubierto para off-record indirect speech (término acuñado en inglés por P. Brown, Levinson, 1987).

6 De aquí en adelante: el discurso indirecto desvelado para on-record indirect speech. 
del principio de cooperación de modo 7 facilitan efectivamente la cooperación misma al garantizar unas condiciones éticas y psicológicas mínimas para que el interlocutor empiece a colaborar en el intercambio de información.

Los estudios posteriores que se han hecho en el campo de la lingüística cognitiva se han prestado a complementar la investigación precedente con el estudio de unas formas del estilo indirecto (el estilo indirecto encubierto) desde la perspectiva psicolingüística que entiende la personalidad del hablante en su dimensión afectiva, emocional o ética como el factor clave para decantarse por la estrategia del estilo indirecto encubierto (Pinker y Lee, 2010). El hablante que se empeña en evitar el riesgo de posibles consecuencias tras haber cooperado en un acto poco ético, aprovecha precisamente las implicaturas conversacionales, y más en concreto su rasgo de poder ser interpretadas (exclusivamente) en el contexto. De acuerdo con eso, el significado implícito de un acto socialmente inaceptable queda fácilmente anulado si el receptor decide no cooperar en el intercambio. De este modo, la violación de una de las máximas de conversación como característica intrínseca de las implicaturas conversacionales resulta una opción discursiva y estrategia acertada. El hecho de que el significado implícito de una proposición pueda anularse fácilmente a condición de que se modifique el contexto inicial repercute positivamente en la disponibilidad del emisor para participar en la conversación aunque esto suponga para él un coste ético y emocional considerables. En la clasificación de funciones psicolingüísticas del discurso indirecto de Pinker y Lee (2010), y Pinker, et. al. (2008) este rasgo estratégico recibe el nombre de la denegación plausible (plausible deniability).

\section{Discusión}

Se procede a analizar, a continuación, algunos casos en concreto del estilo indirecto encubierto en función del criterio que mejor define y más exhaustivamente describe su valor discursivo. Se acude a la sistematización de Grice, pero solo parcialmente, ya que ésta propone el criterio de la no-convencionalidad propio a todas las implicaturas conversacionales (aparte del estilo indirecto encubierto, también a las proposiciones ambiguas e implicaturas que descartan uno o más principios de cooperación) que no restringe el discurso indirecto propiamente dicho de tres tipos de implicaturas conversacionales. La teoría griceana parece algo insatisfactoria precisamente por su falta de exhaustividad

7 «Avoid obscurity of expression. Avoid ambiguity. Be brief (avoid unnecessary prolixity).» (Grice, 1975: 308) 
y precisión para abarcar todas las manifestaciones del habla indirecta. A saber: todo tipo de discurso indirecto hace parte de las implicaturas conversacionales en las que solo el conocimiento de condiciones específicas que han rodeado la creación del mensaje (la intención, las expectativas, la personalidad y la disponibilidad de interlocutores para la cooperación) hace posible descifrar el significado implícito sin tener que acudir a un conocimiento compartido. El criterio no es reversible, ya que no todas las muestras de implicaturas conversacionales corresponden al discurso indirecto en el sentido estrecho; basta con compararlas con una presuposición ambigua cuya arbitrariedad conversacional depende completamente del conocimiento del contexto (para saber a quién se refiere la pregunta posterior en (8) y si la actividad de ayudarse en (9) implica una acción reflexiva o recíproca):

(8) «Yo pensando en imposibles y ella hablando de política. ¿Por dónde irá ahora?» (Ángel Vázquez, 1990, CREA; la cursiva es nuestra).

(9) «[...] después de la misa, ya a los alrededores y por donde ustedes fueran a pasear, y a los alrededores de la iglesia, *habían una cantidad de personas que se ayudaban $[. ..] . »(\mathrm{CSHC}-87,2003, \mathrm{CREA})$

Con todo, procede introducir un criterio más restrictivo o especificativo para definir el discurso indirecto encubierto dentro del panorama de implicaturas conversacionales. Un aspecto distintivo que permite discernir, según Grice, todas las implicaturas conversacionales de las convencionales es su indisolubilidad de la forma en la que están expresadas. Todas las manifestaciones con el significado implicado por el contexto de la conversación presentan este aspecto distintivo por lo que no es posible entenderlo como un factor diferenciador entre las formas del discurso indirecto encubierto y, por ejemplo, las proposiciones ambiguas cuyo cambio formal (añadiendo los pronombres respectivos como en (11) resulta en un cambio de la implicatura conversacional relacionada con la acción verbal (reflexiva/recíproca). Por otro lado, el cambio formal no suele producir ningún cambio significativo en las implicaturas adheridas a las fórmulas convencionales cuyo significado, determinado y acordado por la convención entre los hablantes suele mantenerse invariable e independiente del contexto conversacional (como se puede apreciar en las peticiones implícitas enumeradas en (12), (13) y (14):

(10) *habían una cantidad de personas que se ayudaban entre sí (op. cit.; la cursiva es nuestra)

(11) *habían una cantidad de personas que se ayudaban a sí mismas (op. cit.; la cursiva es nuestra) 
(12) «¡Oye, no te importaría de verdad ya que estás aquí bueno pues me tocas el mamotreto este me lo tocas y me arreglas unos días?’ (petición implícita, op.cit.)

(13) « ¿Oye, podrías tocar ya que estás aquí bueno pues tocar el mamotreto este me lo tocas y me arreglas unos días?» (op.cit.)

(14) «Oye, si no te importa de verdad, ya que estás aquí bueno pues puedes tocar el mamotreto este me lo tocas y me arreglas unos días?» (op.cit.)

La indisolubilidad es una característica inherente a toda implicatura conversacional, por lo que no puede ejercer de marca exclusiva de un solo tipo de implicatura conversacional, como por ejemplo, en discurso indirecto encubierto, ya que está presente en las proposiciones con un valor doble (reflexivo, recíproco en estilo indirecto encubierto).

Por último, entre las características distintivas del significado conversacional implícito Grice (1989: 44) destaca la cancelabilidad que se refiere al hecho de que toda la implicatura conversacional pueda ser cancelada o denegada según cambia el contexto de la enunciación del emisor al receptor, eso es, puede ser completamente aceptada o denegada en el caso de que el receptor no perciba su significado intencionado según los principios éticos, morales o afectivos del emisor, sino lo reinterprete según sus propios principios. A diferencia de las implicaturas convencionales, el significado no queda unívocamente determinado por una convención de un código cultural común compartido por los dos interlocutores, sino que su arbitrariedad permite que cada interlocutor dote el significado implícito de una interpretación que mejor le conviene de acuerdo con sus preferencias emocionales y éticas en la situación concreta de la enunciación. La cancelabilidad de la enunciación se comprueba cuando es posible encontrar una situación donde la forma de la expresión simplemente quita la implicatura y se anula su veracidad. Ésta sirve para definir, de manera más exhaustiva, un número de manifestaciones indirectas que no se incluyen en la investigación de Grice y presentan un alto grado de riesgo emocional potencial (como la petición, amenaza, calumnia o degradación) para el emisor. El hecho de revestir el significado en estilo indirecto encubierto le sirve al emisor como estrategia para minimizar el riesgo potencial que supondría la colaboración en una tarea comunicativa, dando opciones de reinterpretar o rechazar el significado intencionado.

En los tres casos analizados del discurso indirecto encubierto en castellano $(16,17,18)$ evaluamos el principio de la cancelabilidad como un criterio lógico fiable para identificar y definir el discurso indirecto encubierto en 
castellano, y enmarcarlo dentro de los fenómenos discursivos cuyo significado es una combinación de factores psicolingüísticos (expectativas, reacción afectiva, responsabilidad moral) y no exclusivamente sociopragmáticos, como las convenciones de cortesía y el código moral (en relación con estos últimos presentamos en (15) las implicaturas discursivas convencionales). Para ello, se ha sometido los ejemplos al análisis del criterio de denegación en dos vertientes:

a) hasta qué nivel el mensaje implícito en cada frase indirecta se cancela contextualmente si la situación cambia del emisor al receptor a medida que crecen las exigencias morales y emocionales:

b) hasta qué nivel se le puede encontrar al mensaje implícito una objeción o denegación lógica que quita la veracidad al significado intencionado de la frase (el criterio de la (no)veracidad)

(15) «[...] después de la misa, ya a los alrededores y por donde ustedes fueran a pasear, y a los alrededores de la iglesia, *habían una cantidad de personas que se ayudaban, *pero no mútuamente. (CSHC-87, 2003, CREA, la cursiva es nuestra)

(16) Podría añadir también que, en el caso de que Usted tuviera cualquier información que facilitara la ejecución de mi deber no sería penalizada. Efectivamente, todo lo contrario, será premiada. Y ese premio consistirá en que su familia dejará de ser agredida de modo cualquiera por el Ejército alemán mientras que dure nuestra ocupación de su País. ${ }^{8}$ *Pero esto no quiere decir que le esté amenazando. (Tarantino: 2009; la cursiva es nuestra)

(17) A: ¡Jo! ¡aqui bace un frio!

B: Pues yo he salido a la calle y no...

C: Frío no ha hecho.

A: No sé por ahí fuera, pero aquí dentro... *Pero no quiero decir que te esté pidiendo que pongas la calefacción. (Briz, et. al. 2002: 324, la cursiva es nuestra)

8 El ejemplo citado está sacado de un diálogo de la película Los Malditos Bastards (The Inglorious Basterds; Universal Pictures, 2009) del director Quentin Tarantino que trata el tema del enfrentamiento entre el ejército alemán y los bandos de resistencia en Francia durante la Segunda Guerra Mundial. El contexto del diálogo consiste en la interrogación entre un comandante nazi y el campesino francés que colabora con los bandos de la resistencia en el rescate de los judíos perseguidos en holocausto. Durante la interrogación se le propone al campesino desvelar los nombres de las personas perseguidas, a lo que bajo la amenaza extrema de una liquidación en el caso de rechazar la colaboración, accede. La traducción al castellano es nuestra. 
(18) A (novio de B): Siento que que- antes de, de poder, dee, es que yo sé que ella necesita muchas cosas que, que- yo le tengo que dar y no, no tengo tiempo para dárselas.

C (amigo se A): Me parece que estás sacando

D (amigo de A): Bueno tío, pero...

C: El problema de quicio...

B (novia de A): ¡Ye, tías! Os estaba buscando. Tía, ¿̨qué hacéis?

A: Nada, charrar?.

C: Aquí.

D: Nada.

A: Charrábamos.

B: ¿De qué?

D: Nada. Pero no te estábamos calumniando. (Briz, et. al. 2002: 74, la cursiva es nuestra)

En el ejemplo de la proposición ambigua presentado (15) resulta difícil encontrar una objeción ficticia o real que pudiera completamente anular la semántica intencionada de la frase; si la intención principal del emisor es informar sobre una acción ejecutada mutuamente, el receptor no puede objetivar el hecho de que se trate de un significado recíproco, sosteniendo que, por ejemplo la acción de ayudarse, recae sobre las mismas personas que la ofrecen (a sí mismas) sin caer en una contrariedad, paradoja o falsedad con la interpretación reflexiva.

Por otro lado, el ejemplo del estilo indirecto encubierto citado (16) representa una amenaza indirecta camuflada de oferta de colaboración para la consecución de un premio que, en el mejor escenario del desenlace posible, resulta beneficioso para el que recibe la oferta (el campesino amenazado). El amenazador puede lanzar la oferta esperando que en el mejor de los casos, el receptor la acepte bajo la concesión de colaborar en el asunto y en el peor de los casos, lo rechace denunciando al hablante por haber propuesto una amenaza indiscreta. Barajando las dos opciones en una situación que resulta altamente comprometida, el emisor decidirá cuál le facilitará el mayor éxito en la consecución de su objetivo (conseguir la información deseada consistente en la amenaza) a menor coste de represalias posibles (como la denuncia) y hará de acuerdo con esta motivación psicolingüística los reajustes posibles en la forma de expresar su proposición para minimizar la posibilidad de unas consecuencias

9 De acuerdo con el corpus oral seleccionado se incluyen también los casos del español coloquial; los usos no normativos de la lengua se marcan con un asterisco. 
negativas. Por lo tanto, a la implicatura inicial se le puede aducir una objeción que permite, a la par, una interpretación del significado alternativa y menos comprometida para el emisor y una anulación completa de la semántica inicial de la enunciación.

El mismo aspecto de cancelabilidad se puede apreciar en el ejemplo (17) en el que el uso del estilo indirecto encubierto genera a la vez dos implicaturas (afirmación basada en una experiencia empírica/la solicitud de un favor), cuyas cargas emocionales para el emisor resultan diferentes según se trata del mero hecho de informar objetivamente o de la expresión de un deseo que posiblemente supone el riesgo de un compromiso o rembolso demasiado altos por parte del receptor. Por este factor psicológico resulta plausible y estratégicamente más acertada la posibilidad de ofrecerle al receptor dos interpretaciones del significado siempre con la posibilidad de poder cancelar la implicatura de la interpretación que resulte más perjudicial para el emisor.

Al aplicar la prueba de la cancelabilidad al discurso citado (18) se comprobó una vez más que, dadas las dos posibilidades de interpretación del significado implícito (en este caso se trata de una conversación neutral/calumnia), el discurso indirecto encubierto siempre optará por ofrecer la que puede afectar de una manera menos negativa a la imagen ética o emocional del interlocutor dando así la posibilidad de agregar una objeción a la proposición expresada que anula el significado implícito adversario (la calumnia) y se ajuste más a la perspectiva esperada del receptor (una conversación neutral) sin que por eso resulte inadecuada o contradictoria al contexto de la situación.

La teoría cognitivista recupera el aspecto de la cancelabilidad como un rasgo del discurso indirecto encubierto que el hablante usa estratégicamente cuando no está completamente convencido con qué tipo de interlocutor está interactuando - cooperativo o adversario. A pesar de que la intención del hablante esté implicada en el estilo indirecto encubierto, ésta puede obtener un valor significativo completo solo en el contexto concreto de la conversación que aumenta la importancia de la figura del hablante y minimiza el nivel de la certeza y el papel de un conocimiento común compartido. La teoría de la denegación plausible se presta a explicar estos factores relacionados con la psicología de los hablantes para entender por qué los hablantes intencionalmente evitan intercambiar mensajes en una forma que sea clara, concisa, verdadera y relevante, como el estilo indirecto encubierto. De esta manera esta teoría complementa la teoría de cooperación que ha podido dar una respuesta satisfactoria a una parte de las implicaturas como las fórmulas de cortesía y las implicaturas 
conversacionales indirectas, pero que se ha quedado corta en explicar el fenómeno del discurso indirecto encubierto. La interacción humana no es una transacción lineal de datos como el sistema de la radiografía, sino que en su base evolutiva comprende el mutuo esfuerzo de los interlocutores para encontrar dentro de un sistema asimétrico del intercambio de información un modo de cooperar cuánto más efectivo y equilibrado posible:

La comunicación humana [...] es una serie de muestras alternantes de comportamientos entre animales sociales con sus sensibilidades, sus estratagemas y sus dobles intenciones. Cuando ponemos nuestras palabras en los oídos de otros, lo hacemos con el propósito de revelarles nuestras intenciones, sean o no honorables, e influir en ellos tan directamente como si pudiéramos tocarlos con nuestras propias manos. (Pinker 1994: 250)

Este hecho cambia el propósito conversacional de la teoría de imagen social por él de una cooperación mutua equilibrada que usa los elementos discursivos para mitigar el desequilibrio a través de una serie de acciones compensatorias, a través del discurso o la reinterpretación de la situación cuando los costes y los beneficios para uno o ambos hablantes no resultan equilibrados. A medida que crece la discrepancia entre los costes y los beneficios en favor de los últimos, aumenta la posibilidad del éxito de la conversación y disminuye la necesidad de recurrir a unas estrategias compensatorias; sin embargo, la dinámica opuesta que posiblemente represente un riesgo potencial para el hablante aumenta la necesidad de usar una de las estrategias del discurso implícito. Entre los factores principales que favorecen la preferencia de un discurso implícito indirecto, Pinker enumera tres: (1) la distancia social entre el emisor y el receptor; (2) la fuerza respectiva del receptor sobre el emisor; (3) el nivel de la imposición inherente en la proposición del emisor (Pinker y Lee 2010: 787).

La preferencia del uso de unas fórmulas de evasión en implicaturas conversacionles como el estilo indirecto encubierto en situaciones de compromiso o alto riesgo para el receptor parecen apoyarse en datos empíricos. Según los resultados de la investigación sobre los tipos de discurso preferidos por los hablantes anglófonos en situaciones de diferentes grados de compromiso equivalentes a las que se han propuesto para el castellano (la insinuación sexual, el chantaje y la amenaza), una situación de menor riesgo potencial a la imagen social requería las fórmulas de cortesía y los tipos del estilo indirecto desvelado frente al discurso indirecto (junto con otras implicaturas conversacionales), cuyo uso aumentaba respectivamente con la aseveración de las condiciones del 
contexto situacional para los hablantes (dando el $91 \%$ de las respuestas ${ }^{10}$ en los casos de seducción, el $86 \%$ en los casos de amenaza, y el $34 \%$ en la situación del chantaje según Pinker y Lee, 2010: 789). En concreto, según el número de hablantes que prefirieron usar el estilo indirecto encubierto en cada una de las situaciones enumeradas, éste parecía ser una estrategia más acertada que otras formas más directas precisamente por su rasgo de cancelabilidad que permitía al hablante denegar la proposición (indeseada).

\section{Conclusiones}

El análisis cualitativo de los casos de amenaza, petición y degradación (calumnia) indirectas sugiere unas apreciaciones muy esquemáticas sobre el uso del discurso indirecto en transacciones conversacionales. Según parece, la concepción cognitivista puede ofrecer una respuesta alternativa en el análisis discursivo del fenómeno de estilo indirecto; una respuesta que ciertamente resulta parcial puesto que solo abarca un enfoque psicolingüístico propuesto por la teoría de la denegación plausible, pero no por esto pierde su importancia en el panorama de investigaciones que se han ocupado de enmarcar el fenómeno dentro de la pragmática, la teoría del discurso y la sociolingüística.

El presente trabajo ha presentado la teoría de la cooperación e implicaturas conversacionales de Grice $(1975,1989)$ como un punto de partida para describir el fenómeno del discurso indirecto cuya evaluación como una de las herramientas del análisis pragmático-discursivo del estilo indirecto encubierto en castellano ha indicado una insuficiencia de criterios fiables para definir un tipo de discurso indirecto encubierto junto con todos los factores psicolingüísticos que intervienen en su uso comunicativo. Con este motivo se ha introducido alternativamente un análisis cognitivista que, al tener en cuenta los factores mentales y psicoafectivos que intervienen en la formación el discurso, parece ofrecer una descripción más precisa y exhaustiva.

\section{Bibliografía}

Austin, J. (1962): How to do things with words. Oxford: Oxford University Press. Bajtín, M. M. (1981): The dialogic imagination. Austin: University of Texas Press.

10 Un total de 114 personas participaron en la investigación de Pinker y Lee (2010) y evaluaron la preferencia de recurrir en cada una de las situaciones conversacionales montadas a uno de los cuatro escenarios discursivos propuestos, distintos según el grado de la explicitud y cortesía. 
Benveniste, É. (1974): Problemas de lingüística general I y II. México: Siglo XXI, 1971 y 1977.

Brown, P. Y., S. C. Levinson (1987): Politeness. Some Universals in Language Usage. Cambridge: Cambridge University Press.

Bühler, K. (1934/1979): Teoría del lenguaje. Madrid: Alianza.

Goffman, E. (1975): Interaction Ritual: Essays in Face to Face Behavior. Chicago: Aldine.

Gogol, N. V. (1959):»Scinel««. En: L. P. Shuvalova (ed.): Izbrannye proizvedenia. Moscú: Detgiz, 365 .

Grice, P. (1968/1975): «Logic and Conversation». En: Cole et. al.: Syntax and Semantics, 3. Nueva York: Elsevier, 305-314.

Grice, P. (1989): Studies in the Way of Words. Cambridge, MA: Harvard University Press.

Leech, G. N. (1983): Principles of Pragmatics. Longman: Londres.

Pinker, S. (1994 /2001): El instinto de lenguaje. Madrid: Alianza.

Pinker, S.; Nowak, M. A.; Lee, J. J. (2008): «The Logic of Indirect Speech» En: Proceedings of the National Academy of Sciences of the United States of America, 3, 833-858.

Pinker, S. y Lee, J.J. (2010): «Rationales for Indirect Speech: The Theory of the Strategic Speaker», Psychological Review, 3, 787-803.

Real Academia Española (2010): Nueva Gramática de la Lengua Española: Manual. Madrid: Espasa-Calpe.

Searle, J. R. (1969): Speech acts: an essay on the philosophy of language. Cambridge: Cambridge University Press.

Sperber, D. y D. Willson (1994): La relevancia: Comunicación y los procesos cognitivos. Madrid: Visor.

Tarantino, Q. (Director) (2009): Inglorious Basterds. [Motion pictures] Universal City: Universal Pictures.

\section{Fuentes}

Briz, A., et. al. (2002): Corpus de conversaciones coloquiales. Madrid: Arco/Libros.

Real Academia Española: Banco de datos (CREA) [fuente online]. Corpus de referencia del español actual. <http://www.rae.es> [20.6. 2014] 


\author{
Andreja Trenc \\ University of Ljubljana
}

\title{
Conversational Maxims from the Cognitive Approach: some cases of Indirect Speech in the Spanish Language
}

Keywords: Off-the-record, conversation exchange, conversational maxims, plausible deniability, conversational implicatures

The latest investigations in the field of psycholinguistics and sociolinguistics advocate principles of efficient communication in accordance with ethical, logical and psychological dimensions of language use. As a consequence, new theories of interpersonal verbal transactions as a part of cognitive activity (Lee, Nowak y Pinker, 2008; Pinker y Lee, 2010) or politeness theory aimed at the speakers who are negotiating the best linguistic options in order to achieve the desired social purpose (Brown, Levinson, 1987), consider communication as fulfillment of principles of cooperation. The purpose of the paper is to propose alternative criteria for the discourse analysis of phenomena from indirect speech to the present socio-pragmatic cooperative principle (Grice, 1975). The criteria follow psycholinguistic and strategic parameters, such as deniability and cancelability, which are negotiated during an indirect speech act and can be applied to the speech act at the speaker's decision. The paper presents an application of the cancelability parameter to examples of "off-record" indirect speech in Spanish and also refers to some significant data from a research on English Language in order to advocate a psycholinguistic model as a framework which can be used in order to define the "off-record" indirect speech with more reliability and precision. 


\section{Andreja Trenc}

Univerza v Ljubljani

\section{Konverzacijske maksime $\mathrm{z}$ vidika kognitivnega pristopa: nekateri primeri indirektnega govora $v$ španščini}

Ključne besede: prikriti poročani govor, govorna interakcija, konverzacijske maksime, ovrgljivost, konverzacijske implikature

Zadnje raziskave na področju psiho- in sociolingvistike si prizadevajo načela učinkovitega sporazumevanja umestiti v okvire, ki jih predvidevajo etika, logika in psihologija ustreznega jezikovnega vedênja pri rabi jezika. Posledično sodobnejše teorije jezikovnega vedênja kot spoznavne dejavnosti (Lee, Nowak in Pinker, 2008; Pinker in Lee, 2010) oz. vljudnostne teorije med govorci, ki premerjajo najboljše jezikovne možnosti za dosego željenega družbenega cilja (Brown in Levinson, 1987), za razliko od popolnega uveljavljanja sodelovalnih načel sporazumevalno učinkovitost diskurza razumevajo v meri, v kakršni ta upošteva vzorec, ki ščiti govorčevo družbeno in etično podobo. Namen pričujočega dela je ob sociopragmatičnih pristopih, kot je sodelovalno načelo (Grice, 1975), ponuditi nov kriterij, ki upošteva družbeno-jezikovne in strateške parametre, kot sta zanikovalnost in ovrgljivost, ki ju govorec namenoma vključuje $\mathrm{v}$ govor. $\mathrm{V}$ prispevku je ovrednoten parameter ovrgljivosti za konkretne primere prikritega poročanega govora $\mathrm{v}$ španščini in podkrepljen z empiričnimi podatki iz eksperimenta pri angleškem jeziku, in sicer z namenom predstaviti psiholingvistični model kot načelo, ki lahko tip prikritega poročanega govora opredeli $\mathrm{z}$ večjo zanesljivostjo in natančnostjo. 